\title{
INTERVENCIÓN EN LA MESA REDONDA SOBRE LA INFORMACIÓN PARA LA NEGOCIACIÓN COLECTIVA Y EL CONTROL SINDICAL ECONÓMICO, DESDE LA PERSPECTIVA DE LA AUDITORIA SOCIO LABORAL*
}

\author{
ENRIQUe LILLO \\ Abogado. Gabinete Interfederal de Comisiones Obreras (CCOO)
}

DOI: $10.1387 /$ lan-harremanak.17500

Recibido el 30 de septiembre de 2016

Aceptado el 15 de octubre de 2016

\section{SUMARIO}

Sumario: 1. El marco normativo actual solo reconoce derechos a los representantes de los trabajadores en el ámbito de la empresa y no en el ámbito de un sector en donde se desarrolla la negociación colectiva sectorial, ni tampoco contempla unos deberes informativos específicos por parte de la empresa en relación directa e inmediata con la negociación colectiva 2. La única base normativa donde claramente se explicita el derecho a la información vinculado con la negociación colectiva es la que se contempla en el art. 7.2.a) de la Recomendación n. ${ }^{\circ} 163$ de la OIT

* Ponencia con la que participó en la Mesa redonda: Perspectiva profesional de los fundamentos económico-jurídicos para abordar la negociación colectiva y el control sindical económico, en el II Encuentro de Profesionales del Asesoramiento Laboral y Social, celebrado en la Facultad de Relaciones Laborales y Trabajo Social (UPV/EHU-Leioa) el día 30 de septiembre de 2016. 


\section{El marco normativo actual solo reconoce derechos a los representantes de los trabajadores en el ámbito de la empresa y no en el ámbito de un sector en donde se desarrolla la negociación colectiva sectorial, ni tampoco contempla unos deberes informativos específicos por parte de la empresa en relación directa e inmediata con la negociación colectiva}

El actual marco normativo con carácter general sobre derechos de información de los representantes de los trabajadores, independientemente de los procesos de despido colectivo o modificación colectiva sustancial de condiciones de trabajo, se contempla básicamente por el art. 64 del Estatuto de los Trabajadores en relación con el 44 para subrogaciones de empresas o transmisiones empresariales y 42 del Estatuto de los Trabajadores sobre subcontratación de obras y servicios, así como el art. 8.3.a) del mismo texto legal sobre entrega de la copia básica.

Ahora bien, estos preceptos son muy importantes, fundamentalmente el art. 64 del Estatuto de los Trabajadores, especialmente el 64.4.a) donde se establece el derecho de la representación legal de los trabajadores (los delegados de personal según el 62.2 tienen esta misma competencia) a conocer los demás documentos que se dan a conocer a los socios y en las mismas condiciones que estos, y en donde, por tanto, se puede reclamar el acceso a los libros de comercio, como libro mayor, libro diario, inventario, existencias, etc., art. 25 a 30 del Código de Comercio, y art. 196, 197, 256, 255, 262, 272, 278 de la legislación de Sociedades Anónimas y disposiciones concordantes.

Estos derechos de información podrían ser incluso canalizados a través de reclamaciones de conflicto colectivo, de conformidad con el art. 153.3 de la LRJS.

Sobre estos extremos de derecho a información de los representantes se ha efectuado una interpretación rígida por parte de los órganos judiciales y, sin embargo, ha sido muy recientemente cuando se empieza a abrir camino una interpretación más funcional o finalista de las disposiciones legales de los derechos informativos de los representantes legales, puesto que la interpretación meramente literal no facilita muchas veces el acceso a una información que resulta necesaria para la defensa de intereses colectivos de los trabajadores.

En esta línea de interpretación finalista, que tiende a proteger el que realmente los trabajadores puedan realizar sus funciones de vigilancia de la actividad de la empresa para garantizar el cumplimiento de la ley laboral y de los convenios colectivos, cabe citar las sentencias recientes de la Sala de lo Social de la Audiencia Nacional como la de 4 de diciembre de 2015 (AS 2016/97), sobre el alcance del derecho a ser informado de la jornada diaria efectivamente realizada 
por los trabajadores, con entrega de copia del registro donde conste la jornada efectivamente realizada día por día por cada empleado, independientemente de su posible calificación de exceso de jornada para su posterior descanso o de cualquier otra calificación.

Para garantizar este derecho a disponer de copia del registro de jornada diaria efectivamente realizada por cada trabajador y que la empresa está obligada a entregarle a cada uno de sus empleados, la Sala de lo Social de la Audiencia Nacional efectúa una interpretación finalista de los arts. 35.1 y 35.5 y disposición adicional 3. ${ }^{a}$ del Real Decreto 1561/95 de 21 de septiembre.

En esta sentencia se establece que el derecho a la información mensual sobre las horas extraordinarias realizadas solo puede ser operativo y efectivo si se tiene una información no solo de las horas que la empresa califica como extraordinaria, sino de la jornada ordinaria efectivamente realizada, incluso de aquellas horas integradas en la misma que estén ya compensadas con descanso previo o que estén pendientes de compensación posterior, con lo cual no sería compensadas económicamente como horas extraordinarias.

Para garantizar el cumplimiento de esta finalidad de vigilancia sobre horas extraordinarias que atribuye las disposiciones legales a la representación legal de los trabajadores, ésta necesariamente debe conocer y tener acceso a la jornada diaria efectivamente trabajada día a día y poder constatar si realmente se superan o no las horas extraordinarias, independientemente de que la empresa las califique de una manera o de otra.

De ahí que la representación legal tiene que tener acceso a la copia de los resúmenes diarios que se debe entregar a cada trabajador, donde debe constar el registro de cada día de la totalidad de su jornada, de conformidad con el 35.5 del Estatuto de los Trabajadores en relación con las disposiciones legales antes citadas.

Como prueba, también, de esta interpretación finalista mas allá de la mera literalidad que se está innovando por parte de los órganos judiciales cabe citar también la sentencia de la Sala de lo Social del Tribunal Supremo de fecha 24 de febrero de 2016, Rec. 79/2015, Ponente Fernando Salinas Molina, donde se establece, en aplicación de los arts. 32.6, 22.4, 23 y 16.2 párrafo a) de la Ley de Prevención de Riesgos Laborales, que los delegados de prevención deben tener acceso, en las mismas condiciones que la autoridad laboral, a los informes y documentos resultantes de la investigación que la empresa está obligada a realizar en los casos en que se produzca daños para la salud de los trabajadores.

Asimismo, hay que tener en cuenta que el art. 4.2.c) de la Directiva 2002/14 de la CEE, relativa a la información y consulta de los trabajadores en la empresa, establece que la representación de los trabajadores tiene derecho a la 
información y consulta en relación con decisiones de la empresa que pudieran provocar cambios relevantes en cuando a la organización del trabajo y a los contratos de trabajo en la empresa.

\section{La única base normativa donde claramente se explicita el derecho a la información vinculado con la negociación colectiva es la que se contempla en el art. 7.2.a) de la Recomendación n. ${ }^{\circ} 163$ de la OIT}

La Recomendación n. ${ }^{\circ} 163$ OIT versa sobre la negociación colectiva y desarrolla el Convenio 154 ratificado por España de negociación colectiva.

En esta Recomendación 163 se desarrolla la cuestión de los derechos de información y consulta, planteando que deberían adoptarse las medidas necesarias a las condiciones nacionales para que las partes puedan negociar con conocimiento de causa y, en este sentido, se establece el reconocimiento del derecho de las organizaciones de trabajadores a recibir información de los empleadores, como base para negociar con conocimiento de causa y, por ello, en el art. 7.2.a) se establece que, a petición de las organizaciones de trabajadores, los empleadores públicos/privados deberían proporcionar las informaciones acerca de la situación económica y social de la unidad de negociación y de la empresa en su conjunto, que sean necesarias para negociar con conocimiento de causa.

Sin embargo, en este ámbito de información vinculada a la negociación colectiva no hay apenas precedentes judiciales, quizá por ello resulta ilustrativo el estudio y examen de una sentencia del Tribunal Supremo que fue citada en la intervención del Magistrado Carlos Hugo Domenech y que es la dictada por el Tribunal Supremo con fecha 11 de diciembre de 2015, Rec. Casación 15/2015, en la que es parte recurrente la Federación de Servicios de CCOO, representada por este letrado, y parte demandada la corporación de Radio Televisión Española, SA, UGT, USO y Sindicato independiente de comunicación y difusión, sobre conflicto colectivo.

En esta se plantea que no existe acción para reclamar la declaración judicial de que en la negociación del convenio colectivo suscrito entre la Corporación y diversos sindicatos no se suministró una información correcta. La verdad es que la base de la pretensión de conflicto colectivo consistía en que CCOO entendía que la información económica relativa a la masa salarial, que era la base para la negociación del convenio, que se había aportado en la mesa de negociación, no coincidía con la información que se había aportado al Consejo de Administración y que, por lo tanto, se producía una infracción del 64, puesto que en este caso la representación legal tenía derecho a acceder a la información económica que se había aportado al Consejo de Administración y al no haber ocurrido este 
hecho, la falta de información correcta violaba el derecho de libertad sindical y de negociación colectiva, puesto que estos derechos están vinculados a la buena fe y al suministro de la información correcta.

Sin embargo, se entendió que, al no impugnarse el convenio y al no haberse formulado una pretensión concreta de violación de libertad sindical y su consecuencia indemnizatoria, no estamos en presencia de un interés jurídico real y actual susceptible de canalizar una demanda de conflicto colectivo, como la que se planteaba. 